\title{
Method and equipment for the safe development of preparatory workings in the gas-bearing coal seams
}

\author{
Mykola Trokhymets ${ }^{1, *}$, Vira Maltseva ${ }^{1}$, Yehor Vialushkin ${ }^{2}$, Volodymyr Antonchik ${ }^{1}$, Tetiana \\ Moskalova $^{3}$, and Maryna Polushyna $^{3}$ \\ ${ }^{1}$ Institute of Geotechnical Mechanics named by N. Poljakov of National Academy of Sciences of \\ Ukraine, 49005, Dnipro, Simferopolska Str., 2a, Ukraine \\ ${ }^{2}$ National Metallurgical Academy of Ukraine, 49000, Dnipro, Haharina Ave., 4, Ukraine \\ ${ }^{3}$ National Technical University Dnipro Polytechnic, 49005, Dnipro, Yavornytskoho Ave., 19, Ukraine
}

\begin{abstract}
The article describes a method and equipment for the safe development of preparatory working on a gas-bearing, outburst hazardous coal seam by a heading machine. The described method significantly prevents the gas emission during mining operations. Determination of the amount of degassing and relief wells is performed according to the given in article mathematical formulas. This ensures a significant increase in the level of safety processing the preparatory roadway on a gas-bearing, prone to outbursts coal seam by a heading machine. Due to this, the speed of conducting excavation increases and the cost of mining is reduced. The proportionality coefficients of the mathematical models were determined. Mathematical models are used to calculate the number of relief and degassing wells, which are drilled during the impulse hydraulic loosing of the nearby part of the coal seam. Also the duration of liquid injection into a coal seam is also determined. Mathematical models for calculating the number of injection, unloading and degassing boreholes can be used in development of the passports for conducting preparatory workings on a gas-bearing, prone to outburst coal seam by a heading machine with a preliminary impulse hydraulic loosing of the nearby part of a coal seam.
\end{abstract}

\section{Introduction}

When performing mining operations involving the extraction of coal from coal-bearing coal seams, the phenomena such as sudden outbursts of coal and gas into the mined-in space occur. Conditions for the development of coal deposits are extremely diverse. For all this variety of conditions, a universal way of dealing with gas-dynamic events can't be recommended. In addition, with the increase in depth of coal formations in the mines of Ukraine and consequently complication of mining and geological conditions of exploitation, it is difficult to apply measures to prevent emissions of coal and gas. The specialists from such research institutes as the Institute of Geological Sciences of the National Academy of Sciences of Ukraine, Institute of Geotechnical Mechanics named by

*Corresponding author: vleonid1937@gmail.com 
N. Poljakov of National Academy of Sciences of Ukraine, Makiivka State Research Institute for the Safety of Works in the Mining Industry, etc have worked on this problem. The methods and equipment for carrying out the preparatory development of the coal seam by a heading machine are also known $[1,2]$. The disadvantage of these methods is that they do not provide any measures against gas-dynamic phenomena (GDN) during preparatory working at a gas-bearing prone to outburst formation. These ways are dangerous.

The theory of sudden emissions of coal and gas into the worked-out space (working) claims that in order to prevent the gas flow phenomena, it is enough to perform one of the following conditions: reduce the stress state of the gas-bearing coal formation; reduce the gas pressure in the seam (reduce the gas content of the formation); change the properties of the seam [3].

To prevent the outburst of a coal seam when conducting a preparatory roadway, some methods have been developed that apply predrilling of advance relief wells from the working face along the roadway. For example, there is a known method for preventing the outburst in a coal seam when conducting in it a preparatory working with predrilling of advance relief wells from the working face along the roadway with control of their efficiency and further destruction of rock by heading machine at the coal-face. This method is characterized in that the first advance well is drilled in the center of the seam along the axis of working to a depth greater than the depth of the zone with high rock pressure in the nearby part of the working coal-face. The deformation vector of the walls is determined in this well. Then in the plane perpendicular to the deformation vector of the borehole wall, parallel to the first well, in a row from it, first to one wall of the working, and then to the second, the other wells are drilled to a depth equal to the depth of the first well. The diameter of the wells should be no more than $50 \mathrm{~mm}$, and the size of the gaps between the wells is determined depending on the diameter of the wells, the depth of the seam and the physicochemical properties of the strength of the coal in it and the rocks containing it [4].

There is another method of preventing the outburst in a coal seam when conducting a preparatory roadway by a heading machine with predrilling of advance relief wells (here and after ARW) on the working face of the seam. There is another method of preventing the outburst in a coal seam when conducting a preparatory roadway by a heading machine with predrilling of advance relief wells on the working face of the seam. This method is distinguished by the fact that the ARWs are drilled horizontally and parallel to each other from one wall to another wall of the working in the lower part of the coal seam. Then the coal seam, which is located above the ARW plane, is subjected to vibration. At the same time, simultaneously with this process, ARW deformations are measured according to their diameter, which are equal to at least $20 \%$ of their original size [5].

The disadvantage of the methods $[4,5]$ is that they provide only one of the measures against gas-dynamic phenomena. It is the unloading of the nearby part of the working face of the gas-bearing coal seam. They do not provide degassing measures. Moreover, unloading and degassing are carried out simultaneously. Therefore, these methods are not completely safe.

To reduce methane emission from unloaded gas-bearing coal seams during preparatory working, the method [6] has been developed that includes: drilling several wells in the working face of the coal seam, sealing one of them with the possibility of passing water through its sealant and injecting fluid into the coal seam. This method differs in that the remaining wells are sealed with the possibility of free gas vent from the coal seam through sealants, which are tightly connected to a vacuum pump and gas storage, and the fluid is injected into the coal seam in a hydro-pulse mode.

The disadvantage of this method [6] is that it does not provide unloading of nearby part of the working, which is one of the important measures against gas-dynamic phenomena and does not perform simultaneous degassing with unloading. This method is also 
dangerous when conducting preparatory working for gas bearing coal seam by a header machine.

Despite the many developed methods of dealing with gas-dynamic phenomena, none of them guarantees the complete elimination of sudden outbursts of coal and gas. Therefore, the search for new methods and the development of ways for preventing the outburst in a gas-bearing coal seam is an important problem of our time. In this regard, the authors have developed the method of safely conducting preparatory roadway in a prone to outburst gasbearing seam by a header machine, which significantly increases the level of safety of mining operations during preparatory working.

\section{Methods}

This project is based on the task of creating a method that significantly increases the safety of the preparatory working in a prone to outburst gas-bearing seam by a heading machine with applying predrilling of degassing and injection boreholes in the plane of the coal-face, injecting liquid into the injection boreholes, collecting gas released during injection from degassing bore-holes into the gas collector and the subsequent carrying out of development by mechanical destruction of rock at the working face by a heading machine. This method should be characterized that the number of additionally predrilled degassing and relief wells is determined by mathematical formulas. Such an approach should provide that after completion of the process of pumping fluid into injection holes at a distance of at least $30 \mathrm{~m}$ from the coal-face, the following indicators should be simultaneously achieved: the residual gas content in the atmosphere of the sealed part of the working does not exceed $1 \%$ and the strain value of the relief wells at least $20 \%$ of their original diameter. This will provide a significant increase in the level of safety when implementing the method of carrying out preparatory roadway in a prone to outburst gas-bearing seam by a heading machine, since all three conditions are simultaneously fulfilled according to the theory of preventing gasdynamic phenomena: reducing the stress state of a gas-saturated coal formation by deforming the relief holes, reducing the gas pressure in the seam by pumping fluid into the injection boreholes and, as a result, gas displacement from the seam through the degassing bore-holes into the sealed part of the development, as well as the decrease of mechanical properties of the seam as a result of its wetting.

The task is solved due to the fact that in the method of carrying out the preparatory working on a gas-bearing prone to outburst seam by a heading machine the following measures are taken: preliminary drilling of degassing, unloading and injection boreholes in the plane of the coal-face; injection of fluid into injection holes; the collecting of gas released during the injection process from the seam and the working surface into the gas collector; subsequent mechanical destruction of rocks at the coal-face by the combine. Wherein the degassing wells are drilled in the amount determined by the formula

$$
n_{d}=k_{d} \frac{G \cdot S}{D_{d} \cdot t_{i n j} \cdot Q},
$$

where: $G$ - gas content of a coal seam, $\mathrm{m}^{3} / \mathrm{kg} ; S$ - area of working coal-face, $\mathrm{m}^{2} ; D_{d}-$ diameter of degassing wells, $\mathrm{m} ; t_{i n j}$ - duration of fluid injection into the injection hole, s; $Q$ - flow rate of injected fluid into the coal seam, $\mathrm{m}^{3} ; k_{d}$ - proportionality coefficient, $\mathrm{kg} \cdot \mathrm{s} / \mathrm{m}$.

The relief wells are drilled in the quantity, which is determined by the formula

$$
n_{r e l}=k_{r e l} \frac{f}{\gamma \cdot H \cdot D_{r e l \cdot} \cdot t_{i n j}},
$$


where: $f$ - the strength coefficient of rock using the scale of M. Protodyakonov; $\gamma-$ specific weight of rocks, $\mathrm{kg} / \mathrm{m}^{3} ; H$ - distance from the surface on which the preparatory working is carried out, $\mathrm{m} ; D_{r e l}$ - diameter of relief wells, $\mathrm{m} ; t_{i n j}$-duration of fluid injection into the injection hole, $\mathrm{s} ; k_{r e l}$ - proportionality coefficient, $\mathrm{kg} \cdot \mathrm{s} / \mathrm{m}$.

The degassing wells are drilled along the contour of a coal-face, relief wells horizontally in the bottom part of a coal-face, injection holes - in the center. The degassing wells are drilled along the contour of a coal-face, relief wells - horizontally in the bottom part of a coal-face, injection holes - in the center. Before fluid injecting into the injection holes, a leak-free shutoff is installed perpendicular to working axis at a distance of at least $30.0 \mathrm{~m}$ from the coal-face. A vacuum pump is installed in it, which is connected to the gas utilization unit. This pump will pull out the gas that will release from the surface of the face, the degassing and relief wells, the floor of working, the roof and the sides of the mine, then it will be accumulated in the gas collector. And the variable parameters $D_{d}, D_{r e l}$ used in formulas $(1,2)$ are taken so that safe and stable indicators are simultaneously achieved when determining the required duration of fluid injection into the injection holes. The residual gas content in the working atmosphere should be no more than $1 \%$ and the magnitude of relief holes deformation should be at least $20 \%$ of their original diameter.

The gas collector is the space between the surface of the working face and a leak-free shutoff, which is built perpendicular to the working axis at a distance of at least $30 \mathrm{~m}$ from the bottom of the face. The residual gas content in the atmosphere of production between the built wall and the face of not more than $1 \%$ is determined. The magnitude of the relief holes deformation relative to their initial diameter, which should be determined not less than $20 \%$.

The technical result is to increase the level of safety during implementation of the method of carrying out the preparatory working in a gas-bearing prone to outburst seam by a heading machine by making a set of pre-drilled degassing, relief and injection wells with certain quantities and the pattern of their placement on the surface of the working face. This set of wells should be made before impulse hydro-loosening of the nearby part of a coalface, as well as construction of a leak-free shutoff in the working at a distance not closer than $30 \mathrm{~m}$ from the face, simultaneous pumping gas from a sealed wall to a safe level and the making the magnitude of the relief well deformation at least $20 \%$ of their original diameter.

The essence of the invention is explained by the drawing (Fig. 1), which depicts the arrangement of equipment for implementing a method for conducting preparatory work on a gas-bearing hazardous coal seam through a tunnel combine.

The scheme (Fig. 1) consists of a heading machine 1, a drilling mounted rig 2, which is placed on the telescoping jib 3 of the heading machine 1 , a hydro-impulse device 4 , a highpressure pumping unit 5 located on the header 1 , a flexible high-pressure hose 6 , a control panel for the mode of water injecting into the coal seam 7 , leak-free shutoff 8 , vacuum pump 9, gas utilization unit 10, which releases from the surface of the working face, degassing 11 relief 12 and injecting 13 wells, floor 14, roof 15 and sides 16 of the working, gas analyzer 17 , strainmeter 18 , remote indicator 19 and the remote indicator 20 . The working is equipped with the vent conduit 21 and the fire pipe 22 which are connected to a leak-free shutoff 8 .

View A shows the coal-face of the preparatory workings, which shows the degassing wells 11 and the relief wells 12, the injecting well 13, the floor 14, the roof 15, and the sides 16 of the working.

The proposed method is as follows.

Drilling machine 2, for example EBGP-1M, designed by Konotop machine-building plant, which is commercially available for the mining industry, drills a set of degassing 11 
and relief wells 12 in quantities determined by formulas 1 and 2, and one injection hole 13, as shown in Figure $1 \mathrm{~b}$.

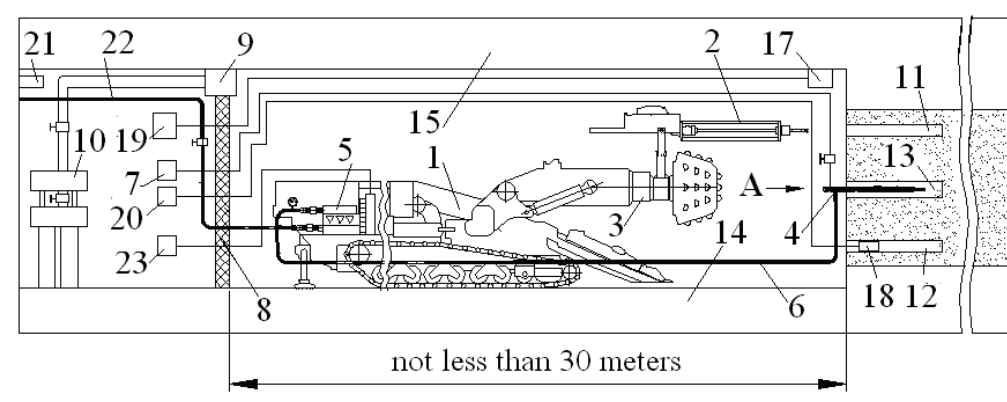

a)

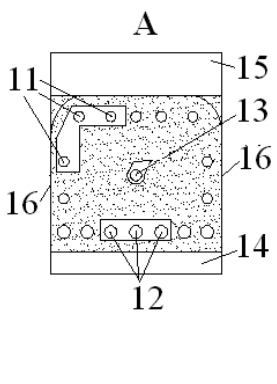

b)

Fig. 1. The layout of equipment for the implementation of the method of preparatory working for a gas-bearing prone to outburst seam with a heading machine: a - in the plane of the preparatory working, $b$ - view A (placement of degassing, relief and injecting wells in the plane of the coal-face).

Heading machine 1 is driven from the coal face of the working and the injecting well 13 on coal seam is equipped with a hydro-impulse device 4 . Then a leak-free shutoff 8 is built and a vacuum pump 9 is mounted in it, the pump is connected to a gas utilization unit 10 . A flexible hose 6 connects a high-pressure pump installation 5 to a hydro-impulse device 4 on the coal seam. The control panel 7 for mode of water injection into the coal seam is placed a sealed wall 8 . The high-pressure installation 5 is connected to the fire pipe 22, in which there is always water under the pressure of at least $0.3 \mathrm{MPa}$. One of the relief wells 12 is equipped with a strainemeter 18 which is described, for example, and the remote indicator 20 of the strainemeter 18 is placed behind a sealed wall 8 .

After that, from the control panel 23, a high-pressure installation 5 is turned on and a fluid (water) is injected into the injection hole 13 according to $[7,8]$. In the process of injecting fluid into the coal seam, the gas release rate between the coal-face and the leakfree shutoff 8 is monitored by the remote indicator 19 of the gas analyzer 17 . As soon as the gas concentration exceeds $1 \%$, the vacuum pump 9 is turned on and the gas released from the degas 11 and relief 12 well, the floor 14, the roof 15 and sides 16 is pumped out from the sealed part of working. The control panel 7 of injection mode of water into the coal seam regulates the mode of the hydro-impulse injection process.

During the injection process the meterage of the remote indicator 20 of the strainemeter 18 is monitored.

The duration of the fluid injection into the injection hole is determined by following indicators, which jointly should be safe and stable. The gas content in the atmosphere of sealed part of the working should be not more than $1 \%$ and the value of deformation of relief wells should be not less than $20 \%$ of their original diameter.

The technical result is ensured by the implementation of all three theoretically possible conditions for preventing gas-dynamic phenomena: reducing the stress state by deforming the relief wells at least $20 \%$ of their original diameter, reducing the gas pressure in the formation, by injecting fluid into the coal seam and, as a result, displacing gas from the seam through the degassing wells 11 and the surface of the coal-face working. The residual gas concentration in the sealed part of working will be not more than $1 \%$, as well as a decrease in the strength indicators of the coal in the seam will be due to its moistening. 


\section{Results and discussion}

Concerning the number of drilled degassing 11 and relief 12 wells, the authors suggest mathematical formulas ( 1 and 2), in which the $k_{d}$ and $k_{r e l}$ are unknown. To determine them the authors provided experimental studies in mine "Krasnolymanska" of the State Enterprise "Coal Company" Krasnolymanska" using the proposed method. The technical conditions were as follows: the depth of the gas-bearing prone to outburst formation $H=$ $611 \mathrm{~m}$; coal type is G; gas content is $0.059 \mathrm{~m}^{3} / \mathrm{kg}$ the specific weight of coal is $2500 \mathrm{~kg} / \mathrm{m}^{3}$; the strength coefficient coal by M. Protodiakonov $f$ is 3 ; seam thickness is $1.7 \mathrm{~m}$; coal-face surface area $S=16 \mathrm{~m}^{2}$; diameter of degassing wells $D_{d}$ is $0.045 \mathrm{~m}$; diameter of relief wells $D_{\text {rel }}=0.05 \mathrm{~m}$; the diameter of the injection well is $0.042 \mathrm{~m}$; the number of relief wells $n_{r e l}=10$ pcs.; the number of degassing wells $n_{i n j}=10$ pcs. Injection parameters are: volume of water pumped by the pump installation 5 UH-35 during the course of mining and experimental research $\mathrm{Q}=2.1 \mathrm{~m}^{3}$; the hydro-impulse device is PGD-0.1, designed by the Institute of Geotechnical Mechanics named by N. Poljakov of National Academy of Sciences of Ukraine (IGTM). The hydro-impulse device construction uses a cavitation generator of the hydro-impulse pressure of a fluid that is injected into the coal seam; the injecting pressure of the fluid is $25.0 \mathrm{MPa}$. One central relief well was equipped with a strainmeter of the IGTM design, adjusted to $20 \%$ deformation of the well walls, and the automatic control equipment was placed at the coal-face of working to produce a visible and sound signal when the $1 \%$ gas content in the atmosphere was exceeded at the nearby part of coal-face. The remote indicator of the automatic control equipment was placed at near the high-pressure unit.

In addition, the KSP-32M heading machine was located in the mine face. The working was equipped with predictive equipment AK-1 located on the mine surface at the premises of the outburst prediction service. This equipment was connected to the communication line of the underground block of sound-absorbing equipment (SAE), which is placed on the side of the mine at a distance of $2.0 \mathrm{~m}$ from the coal-face.

Before experimental work in mine, the heading machine passed $1.0 \mathrm{~m}$ of seam without using measures against gas-dynamic phenomena. The predicted dimensionless indicator of outburst $K_{\mathrm{v}}$ was 3.2. When $K_{\mathrm{v}} \geq 3$, a coal seam is prone to outburst [9].

At the end of the injection of water into the coal seam, the heading machine KSP-32M was moved to the mine coal-face for further mechanical destruction of rocks. At the very beginning of destruction, an outburst prediction of the coal seam was made according to the amplitude - frequency characteristics of the acoustic signal of the sound-absorbing equipment. The predictable dimensionless indicator of outburst $K_{\mathrm{v}}$ was 0.8 . This confirms that the coal seam has become an outburst safe. The research results are: the remote indicator of methane auto control showed that the initial gas content in the atmosphere of the nearby part of the coal-face was $0.05 \%$; after 30 minutes of water injection into the injection wells the gas content was $8.5 \%$; after 60 minutes it was $1 \%$; the indicator of the strainemeter showed a $20 \%$ deformation of the walls of the relief wells of its original diameter.

From the formula (1)

$$
k_{d}=\frac{n_{d} \cdot D_{d} \cdot t_{i n j} \cdot Q}{G \cdot S}, \mathrm{~kg} \cdot \mathrm{s} / \mathrm{m}
$$

Substitution in the formula (3) $n_{d}=10, D_{d}=0.045 \mathrm{~m}, t_{i n j}=3600 \mathrm{~s}, \quad Q=2.1 \mathrm{~m}^{3}$, $G=59 \cdot 10^{-3} \mathrm{~m}^{3} / \mathrm{kg}, S=16 \mathrm{~m}^{2}$, will give $k_{d}=3604 \mathrm{~kg} \cdot \mathrm{s} / \mathrm{m}$.

From the formula (2) 


$$
k_{r e l}=\frac{n_{r e l} \cdot \gamma \cdot H \cdot D_{r e l} \cdot t_{i n j}}{f}, \mathrm{~kg} \cdot \mathrm{s} / \mathrm{m},
$$

Substitution in the formula (4) $n_{r e l}=10, \gamma=2500 \mathrm{~kg} / \mathrm{m}^{3}, H=611 \mathrm{~m}, D_{r e l}=0.05 \mathrm{~m}, t_{i n j}=$ $3600 \mathrm{~s}, f=3$, will give $k_{\text {rel }}=917 \cdot 10^{6} \mathrm{~kg} \cdot \mathrm{s} / \mathrm{m}$.

Thus, thanks to the experimental studies conducted in the mine, $k_{d}=3604 \mathrm{~kg} \cdot \mathrm{s} / \mathrm{m}$ and $k_{\text {rel }}=917 \cdot 10^{6} \mathrm{~kg} \cdot \mathrm{s} / \mathrm{m}$ has been identified.

According to the authors of the patent, these coefficients are universal and can be used for other mining conditions.

At present, preparatory workings in a gas-bearing prone to outburst seam by a heading machine are carried out mainly by a shaking method. This method is carried out as follows: using an electric hand drill SER - 19M the explosive bore-holes on the surface of the working face are drilled out, then they are charged with explosives, workers are taken to a safe distance from the working face and an explosion in the coal seam is carried out. The drilling depth of blast holes is up to $3.0 \mathrm{~m}$.

After the explosive works, the ventilation is made, a header machine is driven into the coal-face part, and only then the mechanical destruction of rock is carried out by the header. All these processes take at least 20 hours. Taking into account the time for heading machine repair and support installation, the maximum daily production output is $3.0 \mathrm{~m}$.

For the implementation of the suggested in this article method, it is possible to use a mechanized drilling of a well set according to a depth of $15.0 \mathrm{~m}$ [1]. This allows to increase the length of daily preparatory working in a gas-bearing prone to outburst seam up to 2 times, that means, the maximum daily output can be $6.0-7.0 \mathrm{~m}$.

\section{Conclusions}

As a result of this work, a new method has been developed, researched and suggested to use for preventing outburst of coal and gas into the mined-out space from gas-bearing prone to outburst coal seams when conducting preparatory workings. The heading complex is also prepared for preparatory workings in prone to outburst coal seams. All this makes it possible to completely solve the problem of the safe caring out of preparation working in gas-bearing prone to outburst coal seams for the extraction of coal from them. Mathematical models for calculating the number of injection, relief and degassing wells are also defined, which can be used during writing of passports for preparatory workings in gas-bearing prone to outburst seams with a heading machine using preliminary hydroimpulse softening of the coal-face.

\section{References}

1. Potapenko, O., Anhelovskyi, O., Vasylev, D., Trokhymets, M., Nykyforov, O., Chuhunkov, I., Antonchyk, V., Vasylev, L., Vialushkin, Ye. (2006). Prystriy dlya mekhanizovanoho burinnya shpuriv $i$ sverdlovyn $u$ vykydonebezpechnomu vuhilnomu plasti pry provedenni $v$ nоти pidhotovchykh plastovykh vyrobok prokhidnytskym kombaynom z robochym orhanom na teleskopniy strili. Patent No 104681, Ukraine

2. www.ngmzbur.com/products/boring-rig/sbn

3. Nikolin, V.I., Vasylchuk, M.P. (1997). Prognozirovaniye $i$ ustraneniye vybrosoopasnosti pri razrabotke ugol'nykh mestorozhdeniy. Lipetsk: Roscompechat

4. Anhelovskyi, O.A., Potapenko O.O., Vasyliev, L.M., Vialushkin, Ye.O., Nykyforov, O.V, Trokhymets, M.Ya. (2015). Sposib zapobihannya vykydonebezpechnosti vuhilnoho 
plasta pry provedenni v nomu pidhotovchoyi plastovoyi vyrobky. Patent No 100004, Ukraine

5. Minieiev, S.P., Potapenko, O.O., Nykyforov, O. V., Anhelovskyi, O. A., Vialushkin, Ye.O., Trokhymets, M.Ya. (2015). Sposib zapobihannya vykydonebezpechnosti vuhilnoho plasta pry provedenni $v$ nomu pidhotovchoyi plastovoyi vyrobky prokhidnytskym kombaynom. Patent No 108176, Ukraine

6. Usov, O.O., Trokhymets, M.Ya., Vasylev, D.L., Poliakov, Yu.Ye., Potapenko, O.O., Anhelovskyi, O.A. (2012). Sposib dehazatsiyi hazonasychenoho vykydonebezpechnoho vuhilnoho plasta. Patent No 68478, Ukraine

7. Vasilev, L.M., Potapenko, O.O., Anhelovskyi, O.A., Vasilev, D.L., Usov, O.O., Trokhymets, M.Ya. (2012). Sposib upravlinnya hidroimpulsnoyu diyeyu na vuhilnyy plast. Patent No 67767, Ukraine

8. Vasilev, L.M., Usov, O.O., Potapenko, A.A. (2011). Prystriy upravlinnya gidroimpulsnoyu diyeyu na vugilniy plast. Patent No 68355, Ukraine

9. Pravyla vedennya hirnychykh robit na plastakh, skhylnykh do hazodynamichnykh yavyshch. (2005). Kyiv: Minvuhleprom Ukrainy 